\title{
PERSPECTIVAS PARA A PARTICIPAÇÃO DO BRASIL NO MERCADO INTERNACIONAL DE PELLETS
}

\author{
M. A. M. E. TAVARES ${ }^{1}$ e S. R. L. TAVARES ${ }^{2 *}$ \\ ${ }^{1}$ Instituto Federal de Educação, Ciência e Tecnologia do Rio Grande do Norte (IFRN) \\ ${ }^{2}$ Centro Nacional de Pesquisa de Solos - (EMBRAPA) \\ silvio.tavares@embrapa.br
}

Artigo submetido em dezembro/2014 e aceito em agosto/2015

DOI: $10.15628 /$ holos.2015.2662

\section{RESUMO}

Este trabalho tem como objetivo analisar o mercado brasileiro para produção e exportação de pellets, um biocombustível sólido, produzido através da compactação da biomassa vegetal. O mercado para esse produto surgiu a partir da crise do petróleo em 1973 e da decisão dos países europeus de reduzirem o consumo de combustíveis fósseis, sob o argumento de que suas emissões contribuiriam para o agravamento do Efeito Estufa. Desde a Conferência de Estocolmo, realizada em 1972, que países da Comunidade Europeia perseguem a meta de reduzirem em até $20 \%$ suas emissões em 2020. Dentre as alternativas para alcançar esta meta está o uso crescente da biomassa como fonte de energia térmica e elétrica, em especial de biocombustíveis adensados de madeira, conhecidos por pellets. Apesar da força e tradição da indústria madeireira, os países do norte europeus, maiores consumidores de pellets, não estão conseguindo mais suprir as próprias demandas, o que vem abrindo o comércio internacional do produto a países de dentro e de fora do bloco, como os EUA e o Canadá. Através do modelo de Heckscher-Ohlin pretende-se demonstrar que, dotado de vantagens comparativas importantes em relação aos demais países produtores, estudos recentes mostram que o Brasil tem condições de participar desse comércio, alavancando suas exportações no setor madeireiro, do qual já é considerado player mundial. Para isso, no entanto, tem que superar as dificuldades provocadas pela falta de uma política de incentivo à produção de energia renovável, além de gargalos de logística que encarecem os pellets nacionais, deixandoos menos competitivos.

PALAVRAS-CHAVE: Biocombustíveis sólidos, biomassa, pellets, bioenergia, comércio internacional.

\section{PROSPECTS FOR BRAZIL'S MARKET SHARE INTERNATIONAL PELLETS}

\section{ABSTRACT}

This work aims to analyze the Brazilian market for the production and export of pellets, a solid biofuel produced by compaction and densification of plant biomass. The market for this product appeared from the oil crisis in 1973 with the decision of the European countries to reduce the consumption of fossil fuels, on the grounds that their emissions contribute to the worsening of the greenhouse effect. Since the Stockholm Conference in 1972 the European Community countries pursue the goal to reduce by $20 \%$ its emissions in 2020. One of the alternatives to achieve this goal is the increasing use of biomass as a source of thermal energy and electricity, biofuels made from densified wood, known as pellets. Despite the strength and tradition of the timber industry, the north
European countries, the largest pellets consumers in the world, are failing to meet the own demands, which led to the opening up of international trade in the product to countries inside and outside the bloc, as the US and Canada. Through the model of Heckscher - Ohlin model, this work intended to demonstrate that, endowed with important comparative advantages over other producing countries, Brazil is able to participate in this trade, leveraging its exports in the timber industry, in which is already considered global player. For this, however, the country must to overcome the difficulties caused by the lack of a policy of encouraging the production of renewable energy, and logistics bottlenecks which increase the national pellets, making them less competitive.

KEYWORDS: Solid biofuels, biomass, renewable energy, bioenergy, international trade. 


\section{INTRODUÇÃO}

Polêmica ou não, a questão do aquecimento global tem direcionado a agenda das nações para a diversificação de suas matrizes energética, com ênfase nas fontes renováveis de energia. Nesse contexto, a biomassa é considerada hoje como uma das fontes de produção de energia com maior potencial de crescimento nos próximos anos (ANEEL, 2008) no mundo e no Brasil. Somente ela tem flexibilidade para fornecer matéria-prima para a produção de energia elétrica e de combustíveis para o setor de transportes (CORTEZ et al, 2008).

Contudo, para que a biomassa se consolide como uma fonte economicamente viável ela depende de processos modernos e altamente eficientes tecnologicamente para sua produção, distribuição e utilização. Esta é uma das razões pelas quais a modernização do uso industrial da biomassa começou pelos países mais desenvolvidos, em especial os países nórdicos, nos quais o mercado de biocombustíveis sólidos manufaturados já está consolidado e em franco crescimento devido às metas de substituição radical dos combustíveis fósseis por fontes renováveis (HALL et al, 2005).

A produção eficiente e sustentável de energia da biomassa traz inúmeras vantagens ambientais, econômicas e sociais se comparada ao uso de combustíveis fósseis, como: melhor manejo da terra, a criação de empregos, o uso de áreas agrícolas excedentes nos países industrializados, o fornecimento de vetores energéticos modernos a comunidades rurais nos países em desenvolvimento, redução nos níveis de emissões de $\mathrm{CO} 2$, o controle de resíduos, a reciclagem de nutrientes, entre outros.

Como a maior parte da biomassa é produzida na zona rural, a sua exploração promove uma maior fixação da população local, gerando empregos, sobretudo para pessoas com pouca ou nenhuma qualificação. Se a produção de biomassa também estiver baseada no cultivo de plantas perenes, de florestas e de plantações com safras anuais para obtenção de matéria-prima alternativa de curto prazo, os benefícios ambientais e energéticos serão ainda maiores. Devemos destacar também o papel importante dos sistemas agroflorestais na obtenção de energia e na diminuição dos níveis de emissão de $\mathrm{CO}_{2}$ - muito mais vantajoso do ponto de vista socioeconômico do que o uso de florestas para sequestrar carbono (HALL et al, 2005).

No que diz respeito ao uso da biomassa florestal, ela ainda é vista com reservas, por estar associada ao desflorestamento e à desertificação, a despeito das técnicas de manejo e das vantagens econômicas das florestas plantadas para fins energéticos e industriais que existem hoje (ANEEL, 2008). O aproveitamento dos resíduos madeireiros e folhosos, juntamente com os resíduos agrícolas e agroflorestais são a base da cadeia produtiva dos biocombustíveis sólidos adensados - os pellets e briquetes.

Neste artigo, são apresentadas análises sobre as perspectivas do comércio internacional de pellets, que pela maior facilidade de manipulação e de um melhor aproveitamento das estruturas logísticas existentes têm uma aceitação muito superior à do briquete no mercado dos países desenvolvidos, os seus maiores consumidores. À luz do Modelo de Heckscher-Ohlin, se procurou estabelecer as razões pelas quais o comércio do produto se desenvolveu no norte da Europa - notadamente nos países nórdicos- e as possibilidades de o Brasil também participar dele. 


\section{CARACTERIZAÇÃO DA BIOMASSA}

Biomassa é todo recurso renovável oriundo de matéria orgânica (de origem animal ou vegetal) que pode ser utilizado para produção de energias elétrica e térmica, além de combustíveis. Podem ser de origem animal (dejetos), florestal (troncos, galhos e folhas), agrícola (soja, arroz e cana-de-açúcar, entre outras) e rejeitos urbanos e industriais (sólidos ou líquidos, como o lixo).

A produção de bioenergia a partir da biomassa de origem animal ainda é muito incipiente no mundo. De acordo com o Atlas da Energia Elétrica do Brasil, até 2008 existiam muito poucas usinas com razoável capacidade geradora de energia, o que não acontece com a produção energética à base da biomassa vegetal.

Dentre as muitas tentativas de conceituar e classificar as diversas fontes de biomassa que existem na natureza sob os mais diferentes critérios, se destaca a classificação apresentada em Nogueira (2005), que separa as biomassas em dois grupos gerais: as tradicionais (não sustentáveis) e as modernas (sustentáveis).

Essa distinção é bastante útil para que possamos entender que o fato de a biomassa ser considerada uma fonte renovável de energia, não quer dizer que ela sempre seja usada de forma sustentável. Um bom exemplo é a lenha. Muitas vezes a vegetação é retirada de forma tão intensa que não dá tempo para que o meio ambiente se recomponha naturalmente. Essa é a causa da maior parte dos processos de desertificação identificados em várias partes do mundo em especial no semiárido brasileiro, que está em vias de se tornar árido devido ao desmatamento da caatinga.

Biomassas tradicionais são aquelas obtidas de forma meramente extrativista, sem reposição. A sua exploração intensa acaba fazendo com que a demanda ultrapasse a oferta, tornando insustentável a manutenção do consumo nos mesmos níveis anteriores. Geralmente são utilizadas domesticamente de maneira rústica, em locais pobres e isolados, para cocção e aquecimento de ambientes, como a madeira de desflorestamento, resíduos florestais e dejetos de animais. Já as biomassas modernas são obtidas de forma legal e certificada, o que significa o uso de técnicas de manejo adequadas de forma a garantir o suprimento futuro. Bons exemplos de biomassas sustentáveis são os biocombustíveis, a madeira de reflorestamento, resíduos agrícolas e agroindústrias, etc. (KAREKESI et al, 2004).

Entre as biomassas modernas (sustentáveis) incluem-se as primárias (produtos de reflorestamentos e resíduos agro-silvi-pastoris) e as secundárias, obtidas a partir do beneficiamento de biomassas primárias através de processos químicos, físicos e mecânicos. Essas biomassas manufaturadas podem ser líquidas (ex: biodiesel, etanol), gasosas (ex: biogás) e sólidas (briquetes e pellets).

\section{A BIOMASSA NO MUNDO}

A biomassa é responsável atualmente por pouco mais de $10 \%$ do consumo final de energia primária do planeta, cerca de $48 \mathrm{EJ} / \mathrm{ano}$, fazendo dela a mais importante fonte de energia renovável utilizada. Evidentemente, o seu grau de utilização varia de país para pais. Em média, a biomassa contribui com menos de $10 \%$ da oferta de energia primária em países industrializados. 
No entanto, em países em desenvolvimento este percentual fica em torno dos 20-30\%, como é o caso da China e do Brasil (International Energy Agency, 2007) ou até mais, conforme Hall et al (2005). Segundo esses autores, em países como Uganda, Ruanda e Tanzânia a participação da energia derivada da biomassa chega a 90\%; na Índia é de $45 \%$.

A larga utilização da lenha nativa pelas nações nesses e outros países subdesenvolvidos é responsável pela impregnação da imagem que a biomassa é uma fonte de energia de uso eminentemente de nações mais pobres. Mas esta imagem vem mudando por três razões: os esforços que estão sendo feitos para o desenvolvimento de tecnologias mais adequadas para explorar o potencial das matérias-primas orgânicas; o reconhecimento dos seus benefícios sociais e ambientais e a crescente utilização das biomassas modernas nos países industrializados.

De acordo com Hall et al (2005), muitos países desenvolvidos também obtêm da biomassa uma quantidade significativa de sua energia total: $4 \%$ nos EUA, $14 \%$ na Áustria, 18\% na Suécia e $20 \%$ na Finlândia - percentuais contudo ainda muito abaixo das previsões mais otimistas dos analistas do mercado energético, a julgar pelo cenário para o ano de 2050, descrito por um dos trabalhos apresentados na Conferência UNCED, realizada no Rio de Janeiro em 1992, no qual as fontes renováveis representariam $3 / 5$ do mercado mundial de eletricidade (17\%) e 2/5 do mercado mundial de combustíveis (38\%) (THE RENEWABLES - Intensive Global Energy Scenario, 1992).

A expectativa de maior participação da biomassa no contexto energético mundial se baseia na constatação que os biocombustíveis podem substituir diretamente os combustíveis fósseis, sem alterar significativamente a atual infraestrutura de suprimento de energia, o que não é possível com as energias renováveis intermitentes, como a eólica e a solar para as quais não se tem um modelo de distribuição e consumo compatível com a infraestrutura que existe atualmente.

Além do mais, os recursos em potencial, como as terras não destinadas à plantação de alimentos e os produtos agrícolas geradores de resíduos têm apresentado uma taxa de crescimento superior à demográfica. Por fim, outro fator que fatalmente contribuiria para o aumento do uso da biomassa energética seria o aumento da demanda provocado pelo crescimento e melhoria das condições de vida das populações dos países de uma forma geral (HALL et al, 2005).

Corroborando para a tese do imenso potencial ainda não explorado da biomassa, Ramage \& Scurlock (1996, apud BOYLE, 1996) estimam que a quantidade de matéria-prima orgânica existente na terra chega a dois trilhões de toneladas - algo em torno de 400 toneladas per capita e de 3.000 EJ por ano - ou seja, mais de oito vezes o consumo mundial de energia primária, que é de 400 EJ/ano.

A Agência Internacional de Energia (IEA), prevê que num prazo de 20 anos, 30\% do consumo mundial de energia serão supridos pela biomassa e outras fontes renováveis. Por enquanto, os dados do Balanço Energético Nacional registram uma pequena redução no consumo mundial de fontes de energias renováveis para fins não energéticos entre os anos de 1973 a 2008, assim também como no consumo de petróleo e carvão mineral como fontes energéticas. Em compensação, o consumo de eletricidade aumentou, o que evidencia um aumento no uso tanto de fontes de energia renováveis para geração de energia elétrica 
(hidráulica, biomassa, eólica; etc) como também da energia nuclear, cuja oferta teve um aumento expressivo.

Em relação à oferta mundial de energia, verificou-se no mesmo período de 1973 a 2008 uma diminuição considerável na participação do petróleo na matriz mundial (passou de $46 \%$ para $33,2 \%$ ), uma estacionaridade com leve tendência de queda das fontes renováveis como um todo, incluindo a biomassa. A participação da energia hidráulica registrou um aumento de quatro pontos percentuais e a do carvão mineral, 2,5\%. O maior aumento de participação na matriz foi da energia nuclear, que era de $0,9 \%$ e passou a representar $5,8 \%$ de toda energia ofertada pelos países de uma forma geral.

A confrontação desses quatro gráficos torna claro que ao aumento do consumo de energia elétrica correspondeu uma maior oferta de fontes renováveis e não renováveis, em detrimento do petróleo, o que explicita o esforço que as nações vêm empreendendo para não se manterem muito dependentes dessa fonte.

Outra comparação oportuna é a da oferta de energia por fonte primária do mundo em 2008 (gráfico 4) com a oferta de energia por fonte primária do Brasil em 2010 (gráfico 5). Mesmo com a defasagem de dois anos entre as duas coletas de dados é possível perceber a diferença da participação das energias renováveis na matriz energética brasileira $(45,5 \%)$ em relação à do resto do mundo (12,2\%). E, dentre as fontes renováveis, a biomassa (lenha, carvão vegetal e derivados da cana) prevalece sobre a energia hidráulica. Segundo Villela (2009), em menor ou maior proporção, essa predominância da biomassa sobre as demais fontes de energia renováveis acontece não só no Brasil como no mundo de uma forma geral.

A representatividade da biomassa na matriz energética brasileira só não é maior porque justamente os resíduos com maior potencial gerador de energia pelo grande volume - os agrícolas - são utilizados na sua maior parte para alimentação humana e animal. O que sobra normalmente é inviável comercialmente devido aos custos de transporte do material bruto (Ministério do Meio Ambiente - MMA, 2011).

Já os resíduos da atividade madeireira normalmente são utilizados na própria cadeia produtiva da indústria que os geram. No processo de extração da celulose da madeira, é extraída a lixívia negra (ou licor negro) usada como combustível em usinas de co-geração da própria indústria de celulose (ANEEL, 2008).

Para alcançar as metas da União Europeia de redução progressiva das emissões de $\mathrm{CO}_{2}$ (20\% até 2020), o consumo de energias não poluentes vem aumentando desde 1995, o que tem estimulado a diversificação da matriz energética no continente. Os analistas da Agência Nacional de Energia Elétrica (ANEEL) estimam que não demorará muito a criação e consolidação do biotrade ou comércio internacional de energia renovável, uma vez que nas transações entre países a comercialização dos biocombustíveis é crescente. "Por isso e por ser um fenômeno iniciado há poucos anos, essa comercialização exige, também, negociações bilaterais e multilaterais que têm, como foco, a regulamentação e a análise das barreiras comerciais e tarifárias já impostas, principalmente por Estados Unidos e da União Européia" (ANEEL, 2008).

Conforme editorial da revista The Economist, "a biomassa tem que ser lucrativa, além de virtuosa" (HALL et al, 2005). Apesar de já serem competitivos em determinadas circunstâncias, a maioria das tecnologias atuais de utilização da biomassa ainda não chegou ao estágio no qual as 
forças do mercado possibilitem sua adoção. Além das dificuldades já citadas acima, duas grandes barreiras ainda devem ser derrubadas para a consolidação da biomassa nas matrizes energéticas dos países - sejam eles desenvolvidos ou não, a saber:

i) os mercados de energia atuais expurgam os custos sociais e ambientais do uso de combustíveis fósseis e os riscos associados a eles, impondo à sociedade vários custos externos. Porém, as fontes de energia renováveis com baixos e até mesmo nenhum custo externo e com uma série de impactos sociais positivos são apresentadas como desvantajosas;

ii) as fontes convencionais tendem a receber grandes subsídios, ao contrário das alternativas.

Logo, "a internalização dos custos e benefícios externos e a relocação mais equitativa dos subsídios devem tornar-se prioridade para que as energias renováveis possam disputar o mercado em pé de igualdade com as não renováveis" (HALL et al., 2005).

\section{A PRODUÇÃO DE BIOCOMBUSTÍVEIS SÓLIDOS ARTIFICIAIS}

Os pellets e briquetes são as formas mais refinadas de biomassa sólida. Ambos podem ser produzidos a partir de matéria orgânica animal e vegetal prensada, tanto para fins energéticos como alimentares (um bom exemplo de pellet alimentar são as rações para animais). Na fabricação dos dois combustíveis podem ser usadas como matérias-primas serragem, maravalha, casca de arroz, palha de milho, sabugo, bagaço de cana-de-açúcar, casca de algodão, café entre outros (QUIRINO, 2012b).

Cada país explora as suas potencialidades biomássicas de forma diferente para produzir seus biocombustíveis sólidos adensados. A Finlândia, país frio e úmido, tem grandes reservas e industrialização de turfa, que é transformada e briquetada ou pelletizada para a produção de energia. A Índia, detentora do maior rebanho bovino do mundo, tem no esterco seco, uma fonte de energia, o qual também é briquetado para uso em fogões domésticos (GENTIL, 2008).

A diferença básica entre briquetes e pellets é a aparência e o processo de produção, determinados pelo fim a que se destinam os dois tipos de combustível. Os briquetes têm geralmente entre $4 \mathrm{~cm}$ e $10 \mathrm{~cm}$ de diâmetro e entre $4 \mathrm{~cm}$ e $40 \mathrm{~cm}$ de comprimento. Por oferecerem uma queima rápida e uniforme, são usados para queima em abatedouros, cerâmicas, cervejarias, destilarias, fecularias, hospitais, hotéis/motéis, indústria de balas, indústria de óleo de soja, indústria de papel, indústria de refrigerantes, laticínios, lavanderias, metalúrgicas, panificadoras, pizzarias, residências e tinturarias (GENTIL, 2008).

Já os pellets costumam ter diâmetro variando entre $0,5 \mathrm{~cm}$ e $2 \mathrm{~cm}$, e comprimento de até $4 \mathrm{~cm}$. Mas Grover \&Mishra (1996, apud Gentil, 2008) definem o pellet como o combustível adensado com menos de $3 \mathrm{~cm}$ de diâmetro e o briquete, maior que este valor. Na verdade, a diversidade de definições é reflexo da falta de normatização sobre os pellets e briquetes quanto a suas características físicas e químicas - um dos entraves para o crescimento desses biocombustíveis no Brasil, já que para um mercado em formação a qualidade do produto é fundamental (GENTIL, 2008).

Para produzir tanto os pellets quanto os briquetes, a matéria-prima deve ser adensada a pressões de $100 \mathrm{MPa}$ (GENTIL, 2008) e comprimida com uma carga média entre 6tf e 8tf e tensão 
de $90 \mathrm{~kg} / \mathrm{cm}^{2}$ a $145 \mathrm{~kg} / \mathrm{cm}^{2}$. O processo de compressão provoca o aquecimento do material numa temperatura que pode ir de $170^{\circ} \mathrm{C}$ a $270^{\circ} \mathrm{C}$, provocando a plastificação da lignina - um aglutinante natural que faz parte da composição de toda matéria orgânica vegetal. $\mathrm{O}$ teor de umidade ideal dos pellets e briquetes é de $8 \%$ e densidade entre $1,0 \mathrm{t} / \mathrm{m}^{3}$ a $1,5 \mathrm{t} / \mathrm{m}^{3}$ (ROWELL, 1987). Normalmente, o processo de produção do pellet é por extrusão contínua numa matriz de furos e o do briquete com pistão mecânico de pulso.

O processo de fabricação de pellets e briquetes é praticamente igual, mudando apenas os equipamentos que ficam no final da cadeia produtiva, cujas fotos estão acima. Os custos diretos mais impactantes no preço final dos dois tipo de combustíveil são relacionados ao início e final da cadeia produtiva - os preços dos fretes da matéria-prima até o pátio da fábrica e os de entrega do produto final, além do preço da matéria-prima (GENTIL, 2008).

A competitividade dos briquetes ou pellets no mercado é função da relação preço/poder calorífico. Quem compra biocombustível adensado compra na verdade energia. Assim, quanto menor o teor de umidade e maior a densidade, maior capacidade energética terão esses combustíveis (GENTIL, 2008).

Além do menor preço relativo (mais energia concentrada num mesmo espaço ocupado por lenha) as outras vantagens dos biocombustíveis sólidos adensados para quem os compra são : uniformidade de temperatura e pressão de vapor, proporcionando um melhor acabamento nos produtos cozidos nos fornos; elevação rápida da temperatura, contribuindo para uma maior eficiência nos processos produtivos; redução de mão-de-obra para carga e descarga; a padronização dos tamanhos permite um melhor aproveitamento dos espaços tanto para transporte quanto para armazenamento, facilitando inclusive a acomodação do produto em containers para exportação.

O fato de serem menores do que os briquetes faz com que os pellets possam ser mais facilmente manipulados e queimados. Outra vantagem está nos custos de produção por unidade de massa/energia. Segundo SERRANO (2009), os custos de manutenção de uma máquina de fazer pellet são menores, já que seu mecanismo não é de impacto, como acontece nas briquetadeiras, mas sim rotativo. Outra vantagem da granulometria diminuta dos pellets é possibilitar um melhor aproveitamento das estruturas logísticas graneleiras. E é por isso que praticamente não existe exportação de briquetes, ao passo que o comércio internacional de pellets tem aumentado expressivamente (CARASCHI e GARCIA, 2012).

\section{O MERCADO INTERNACIONAL DE PELLETS}

Dias (2002) estabelece uma correlação entre o maior uso de pellets ou de briquetes ao grau de desenvolvimento dos países. Segundo ele, os briquetes são mais usados em países em desenvolvimento, onde predominam os fornos mais rústicos e, por isso, menos eficientes. Já os pellets seriam mais usados nos países desenvolvidos, nos quais o seu uso é automatizado, inclusive nas residências.

Uma das razões para essa segmentação do mercado de combustíveis adensados é que, para poder usar pellets, é necessário que o consumidor adquira equipamentos específicos, como fornos e caldeiras de alta eficiência. Para investir neste tipo de maquinário é fundamental que se 
tenha garantia não só do fornecimento como da qualidade do combustível a preços competitivos, o que só é possível com uma indústria bem estruturada (SERRANO, 2009).

Segundo Hayes (2007, apud SERRANO, 2009), tanto a produção quanto o consumo de pellets s energéticos encontram-se concentrados na América do Norte e na Europa. A autora estima que o consumo mundial de pellets em 2007 tenha sido de 7,8 milhões de toneladas (aproximadamente três milhões de tep). Desse total, 6,5 milhões foram consumidos na Europa e 1,2 milhão na América do Norte (os dados são da empresa finlandesa VAPO).

Em 2007 a Europa teve um déficit de produção e precisou importar um milhão de toneladas - exatamente a mesma quantia exportada pelos EUA e Canadá - o maior exportador de pellets do mundo, responsável, por mais de $20 \%$ do comércio internacional do produto. A produção e o consumo no resto do mundo foram de apenas 0,1 milhão de toneladas (HAYES, 2007, apud SERRANO, 2009). De acordo com dados da North American Wood Fiber Review, em 2010 o consumo de pellets na Europa foi de 11,5 milhões de toneladas, superando a produção doméstica, exigindo, mais uma vez a importação de 1,6 milhões de toneladas para os países baixos e Reino Unido.

Há mais de 10 anos que o governo americano e alguns governos europeus vêm subsidiando o aprimoramento e a compra de aquecedores residenciais e comerciais a pellets. Países como a Dinamarca, Suécia, Alemanha, Áustria e Itália consomem, juntos, 1,98 milhão de toneladas do combustível por ano (Rakos, 2007, apud SERRANO, 2009); em outros países, como a Holanda, Bélgica e também a Suécia e Dinamarca, os incentivos governamentais são para a construção de termoelétricas a pellets; a estratégia da França, por sua vez, foi reduzir o imposto equivalente ao ICMS (VAT) de $19 \%$ para 5,5\% para produtos relacionados a pellets, além de restituir metade dos custos de produção (Rakos, 2007, apud SERRANO, 2009).

Essas e outras medidas foram tomadas para viabilizar o cumprimento das metas de redução das emissões de Gases do Efeito Estufa (GEE) em 20\% até 2020. Desde então, o mercado para as biomassas sólidas adensadas, sobretudo os pellets, pelas razões já enumeradas, tem aumentado progressivamente. De 2002 a 2010 o número de fábricas de pellets na América do Norte e na Europa passou de 70 para 623 - um aumento de 890\% (CARASCHI e GARCIA, 2012).

Ainda que o ritmo dessa expansão tenha diminuindo nos últimos anos por causa do equilíbrio entre oferta e demanda (de 2003 para 2004 cresceu 69\% e de 2009 para 2010 cresceu apenas 5\%), isso não quer dizer que o mercado esteja perto de saturar. Pelo contrário. PIGAHT et al. (2010) afirma que o potencial para o comércio de pellets na Europa apenas começou a ser analisado e que há muito espaço para outros países europeus participarem dele, como a Grécia, Espanha e Itália. Esses países poderiam se beneficiar das importações para o desenvolvimento de um mercado interno de caldeira e, das exportações, para possibilitar o planejamento de usinas de pellets maiores.

Os projetos de plantas para produção de pellets têm tido no Emission Trade Scheme uma boa fonte de financiamento. O ETS existe desde 2005 e é atualmente o mecanismo de mercado mais difundido na Europa para compensar as emissões de GEE acima dos permitidos pelas legislações com a compra de créditos das emissões evitadas em outras empresas de dentro e fora dos países. 
Entre os setores da economia que estão submetidos às metas de redução de emissões de GEE está o elétrico. Por isso, as termoelétricas são as maiores demandantes de pellets combustíveis na Europa. É através da substituição parcial de combustíveis fósseis em suas matrizes que estas companhias estão conseguindo reduzir suas emissões. Assim, nos países nos quais os preços de pellets são competitivos, há um maior uso desse bicombustível em sistemas co-geração; já nos países em que este uso não é viável em relação aos combustíveis convencionais, a opção tem sido financiar projetos de Mecanismos de Desenvolvimento Limpo para aquisição futura de créditos de emissões - os chamados European Union Allowances. Dentre os projetos financiáveis estão os de instalação e ampliação de usinas de pellets. "É nesse cenário que o mercado europeu de pellets tem crescido, e tende a crescer ainda mais, tanto na geração de eletricidade quanto no setor de aquecimento residencial" (SERRANO, 2009).

A constituição, em Bruxelas, do Conselho Europeu de Fabricantes de Pellets (EPC European Pellet Council) também sinaliza para a importância que esse mercado vem assumindo no continente. O EPC tem como principal objetivo promover o uso dos pellets como bicombustível, através da implementação de um mecanismo de certificação europeu e da coleta sistemática de informações sobre o mercado. Dentre os países que estão à frente do Conselho estão os maiores consumidores e produtores de pellets do mundo - Suécia, Áustria e Finlândia, lideradas pela Suécia, que produz e consome cerca de 1,4 milhões de toneladas equivalente a $28 \%$ da demanda européia,

A consolidação do comércio internacional de pellets europeu tem explicação nas vantagens comparativas que alguns países do continente apresentam para a produção e consumo desse biocombustível: madeira em abundância e uma indústria madeireira forte, que por sua vez gera grande quantidade de resíduos (tabela 1).Os países do norte europeu, notadamente a Suécia, Finlândia e Dinamarca possuem imensas áreas de florestas plantadas e uma longa tradição de exploração da biomassa de madeira para os mais variados fins, em especial para conforto térmico residencial e comercial, devido ao clima frio na maior parte do ano.

Para atender à demanda do mercado de pellets crescente, a Suécia produziu 1,6 milhão de toneladas em 2008 e importou outras 300 mil toneladas, principalmente, de outros países da Europa e também do Canadá. Não há previsão de qualquer queda na demanda e a taxa de crescimento para os próximos anos deverá se situar entre $8 \%$ e $10 \%$ ao ano (WRI, apud GENTIL, 2008).

Ao estudar os processos de produção do combustível nos principais países produtores e consumidores, Thek \& Obernberger (2002, apud GENTIL 2008) chegaram à conclusão de que a resposta para a liderança da Suécia no mercado de pellets de madeira europeu está nos seus custos mais baixos de produção, que fazem com que o produto tenha um preço mais competitivo (tabela 1).

Tanto na Suécia, quanto na Finlândia e na Áustria, os dois maiores custos de fabricação são os de matéria-prima e secagem da serragem. A Finlândia ainda consegue um custo menor de matéria-prima, mas o da secagem fica bem acima do custo obtido na Suécia, assim como todos os demais custos No caso da Áustria, terceiro produtor de pellets da Europa, todos os custos ficam bem acima daqueles apresentados pela Suécia. 
Apesar de estarem entre os maiores produtores, Suécia, Finlândia, Áustria e outros países europeus consomem boa parte da produção de pellets para atender ao mercado interno. O que falta é importado de nações do próprio bloco que conseguem um excedente maior, como a França. Porém, cada vez mais, os pellets consumidos na União Europeia vêm sendo importados também de países com importante atividade florestal, ainda que fora do bloco, como Estados Unidos e Canadá (SERRANO, 2009).

Tab. 1- CUSTO DE PRODUÇÃO DOS MAIORES PRODUTORES DE PELLETS

\begin{tabular}{|c|c|c|c|c|c|c|}
\hline & \multicolumn{2}{|c|}{ SUÉCIA } & \multicolumn{2}{c|}{ FINLÂNDIA } & \multicolumn{2}{c|}{ AUSTRIA } \\
\hline Etapas & Custo & $\%$ & Custo & $\%$ & Custo & $\%$ \\
\hline Matéria Prima & 31,3 & 51,3 & 28,6 & 34,0 & 32,2 & 34,0 \\
\hline Secagem & 13,0 & 21,3 & 25,2 & 30,0 & 26,5 & 30,0 \\
\hline Cominuição & 2,10 & 3,44 & 3,36 & 4,00 & 3,66 & 4,00 \\
\hline Peletização & 3,60 & 5,90 & 7,56 & 9,00 & 9,15 & 10,0 \\
\hline Resfriamento & 0,50 & 0,82 & - & - & - & - \\
\hline Armazenamento & 3,00 & 4,91 & 2,52 & 3,00 & 2,74 & 3,00 \\
\hline Equip. Periférios & 0,90 & 1,47 & - & - & 3,66 & 4,00 \\
\hline Mão de Obra & 5,50 & 9,00 & 10,9 & 13,0 & 10,9 & 12,0 \\
\hline Construções & 1,40 & 2,20 & 3,36 & 4,00 & 2,74 & 3,0 \\
\hline CUSTO TOTAL (€/ton) & 61,3 & 100 & 84,0 & 100 & 91,5 & 100 \\
\hline
\end{tabular}

Fonte: GENTIL, 2008

Esta tendência de abertura do mercado cada vez mais para um número maior e parceiros é registrada pela European Association Biomass (AEBIOM), segundo a qual os mercados de pellets de madeira residencial e industrial devem consumir entre 50 e 80 milhões de toneladas em 2020 e dependerão de um comércio internacional muito mais abrangente (OLIVEIRA, 2012).

É nesta perspectiva que países com disponibilidade de terras agricultável setor florestal consolidado e clima tropical, podem passar a competir nesse mercado em expansão, ainda que geograficamente mais distantes da Europa do que os Estados Unidos e o Canadá, principais exportadores de pellets fora da Comunidade Europeia. Os custos mais baixos da biomassa madeireira e o aproveitamento de resíduos agrícolas, agroindústrias e florestais são as principais vantagens comparativas desses potenciais players do mercado de biocombustíveis sólidos adensados. Dentre esses países com condições sabidamente favoráveis para a produção de pellets está o Brasil.

\section{PERFIL DA PRODUÇÃO DE PELLETS NO BRASIL}

A primeira planta de pellets para produção de energia que se tem notícia no Brasil é de 1994, da fábrica Battistela, localizada na cidade de Negrinhos, em Santa Catarina e que existe até hoje produzindo pellets de madeira(OLIVEIRA, 2012). De acordo com dados da Associação Brasileira das Indústrias de Biomassa, existem cerca de oito fábricas de pellets no País e todas elas com volume muito baixo de produção - menos de 350 toneladas mensais. Gandes empresas, como a Suzano Energia Renovável, anunciaram, ainda para 2012, vultosos investimentos na construção de fábricas de pellets de madeira na região nordeste. 0 projeto audacioso prevê a construção de uma das maiores plantas industriais do produto no mundo, com produção estimada de 1 milhão de toneladas ao ano (CARASCHI e GARCIA, 2012). 
A cadeia produtiva conta com diversos tipos de fornecedores de matéria-prima: empresas reflorestadoras, agroindustriais (principalmente do setor canavieiro), serrarias, laminadoras, fábricas de compensados e painéis de madeira reconstituída, agroindústrias, até prefeituras que entregam restos de podas urbanas e trabalhadores rurais que vivem de atividades extrativistas, como é o caso dos carnaubeiros do Rio Grande do Norte e do Ceará. Um resumo desta cadeia produtiva pode ser vista no gráfico abaixo.

Em países como Canadá, EUA, Suécia, Áustria e Finlândia uma produção pode ser chamada de grande porte quando superar as 10 mil toneladas por mês; já no Brasil, por ser uma atividade ainda em formação, são raras as empresas que têm capacidade de produzir 1000 toneladas por mês (GENTIL, 2008). A baixa produção é, ao mesmo tempo, causa e consequência da lentidão com que o Brasil tem respondido às demandas crescentes de combustíveis adensados no exterior.

Em primeiro lugar, os consumidores em potencial dos pellets no Brasil praticamente não conhecem o produto e, os que conhecem, ainda não confiam nas suas qualidades. Uma das razões para essa baixa aceitação é a falta de padronização e de formação de um mercado local (OLIVEIRA, 2012).

Outros problemas apontados pelos produtores de pellets no Brasil são: a falta de uma política nacional de incentivo ao uso dos resíduos florestais e agrícolas para geração de energia e os altos custos do transporte da matéria-prima para a fábrica e, desta, para o mercado consumidor, seja ele interno ou externo (SERRANO, 2009).

Outro entrave para a consolidação do negócio de pellets no País é a dependência de importação de máquinas peletizadoras. Ao contrário das briquetadoras nacionais, as peletizadoras produzidas aqui não conseguem processar a enorme gama de resíduos agrícolas e madeireiros que chegam às fábricas - são adaptações de peletizadoras para fabricação de ração animal, sem a resistência nem a robustez necessárias para a produção de pellets energéticos.

Para ser economicamente viável, uma fábrica de pellets deve ter capacidade para produzir, no mínimo 350 toneladas por mês, o que significa um investimento de mais de $\mathrm{R} \$ 2$ milhões, de acordo com informações da Lipel, uma das empresas que fabricam equipamentos para fábricas de briquetes e pellets no Brasil - investimento esse que, diante dos problemas mencionados acima, nem sempre se mostra viável. Contudo, apesar desses gargalos na produção e escoamento do produto rumo ao mercado externo, as vantagens comparativas que o País tem no mercado de resíduos agro-silvi-pastoris indicam que há espaço para ele no comércio internacional de pellets.

\subsection{VANTAGENS COMPARATIVAS DO BRASIL PARA A PRODUÇÃO DE PELLETS}

As vantagens comparativas do Brasil na produção estão ligadas aos fatores de produção mais intensivos nessa atividade: recursos naturais e a mão de obra pouco qualificada.

O Brasil tem uma extensão territorial de $8.514 .877 \mathrm{Km}^{2}$, que correspondem a 851,4 milhões de hectares, dos quais 477,7 milhões são ocupados por florestas naturais (63\%). Além delas, conta com 7,6 milhões de ha de florestas plantadas que, apesar de equivalerem a $0,8 \%$ do território (a Suécia, menor que o Estado da Bahia tem 8,8\% de seu território ocupado por florestas plantadas), o que coloca o país no 70 lugar do ranking mundial de áreas plantadas 
(gráfico 13). O restante do solo é usado para pecuária $(20,8 \%)$ e outros usos $(15,4 \%)$, dentre os quais a agricultura. Ou seja, a quase totalidade das terras do Brasil é utilizada em atividades geradoras de biomassa vegetal.

De acordo com dados da versão preliminar para consulta pública do Plano Nacional de Resíduos Sólidos (Ministério do Meio Ambiente - MMA, 2011), a estimativa de geração de resíduos nas agroindústrias associadas à agricultura é de 291 milhões de toneladas por ano (69\% oriundos de produtos da cana-de-açúcar); em relação aos resíduos animais, considerando apenas as criações intensivas, o volume de resíduos chega a 365 milhões de toneladas/ano, além de mais 266 mil toneladas/ano de resíduos das agroindústrias associadas à pecuária. Já os resíduos florestais correspondem a 85,6 milhões $\mathrm{de}^{3} / \mathrm{ano}$, gerados em duas etapas da cadeira produtiva da madeira (colheita e processamento mecânico).

O Brasil tem hoje o quarto maior parque de serrarias e a 11으 maior produção de papel e celulose do mundo. O saldo crescente da balança comercial no setor florestal demonstra a pujança do setor. Da indústria de papel e celulose aproveita-se o licor negro, usado para cogeração nas empresas. Os resíduos gerados pelos setores de madeira e móveis são basicamente maravalhas e cavacos, os quais poderiam ser mais bem aproveitados para geração de combustíveis com maior poder de queima como os briquetes e pellets.

Enquanto , países com tradição na exploração de recursos florestais, como o Canadá e os EUA estão hoje entre os maiores exportadores de pellets para a Europa, este produto não consta da pauta de exportações do setor madeireiro brasileiro, país que também está entre os maiores exportadores de produtos madeireiros e que detém o maior índice de produtividade de suas florestas plantadas (gráfico 15). Dois exemplos do potencial de produção de biomassa das florestas tropicais brasileiras podem ser observados no gráfico 16.

O aproveitamento dos resíduos agroindustriais e florestais poderia contribuir com 25,904 GW/ano a mais para a oferta de energia do País. Isso, sem contar com o licor negro usado na cogeração de energia elétrica das indústrias de papel e celulose e com os resíduos agrícolas, não contabilizáveis (Ministério do Meio Ambiente - MMA, 2011). A utilização da biomassa já disponível na natureza na fabricação de combustíveis adensados poderia triplicar sua contribuição para a pauta de exportação dos produtos de origem florestal, saltando dos atuais e US\$ 7 bilhões (3,2\% do comércio mundial), para algo em torno de US\$ 20 a 25 bilhões ( $10 \%$ do comércio mundial atual).

A todas essas vantagens se soma mais uma: como a principal fonte de energia elétrica do Brasil é renovável e barata (hidráulica), o País não depende dos pellets para gerar sua energia, ainda que consuma o produto em algumas cadeias produtivas específicas. Com isso, pode ter um excedente considerável para exportar - coisa que, como já visto anteriormente, a maioria dos consumidores de pellets não tem.

\subsection{TEOREMA DE HECKSCHER-OHLIN}

SERRANO (2009) considera que a região sul do Brasil, seja a mais competitiva para participar do comércio internacional de pellets, em função da grande concentração da silvicultura principalmente em Santa Catarina e Paraná da concentração da indústria madeireira na região, da existência de uma infraestrutura mínima de logística na região, além do fato de a produção 
florestal ser majoritariamente certificada, o que é fundamental para a conquista do exigente mercado de produtos ambientais europeu.

O autor analisou a viabilidade econômica de uma unidade industrial com capacidade de produção de 100.000 toneladas de pellets por ano, considerando a produção no Paraná, o embarque no porto de Paranaguá, com destino ao Porto de Rotterdam, na Holanda, onde o biocombustível seria vendido a granel para fins industriais e/ou para combustível em geração termoelétrica.

A conclusão a que ele chegou é que a produção e exportação de pellets do Brasil para a Europa pode ser viável, em função do preço mais baixo de algumas matérias-primas, algumas dispensando a operação de secagem, que de acordo com as tabelas 2, 3 e 4 podem significar de $20 \%$ a $30 \%$ do custo de produção on farm dos maiores produtores de pellets.

Partindo-se então do pressuposto de que pode ser viável, a fundamentação teórica para justificar a inserção do Brasil no mercado de biomassa em geral e de pellets em particular vem do teorema de Heckscher-Ohlin, segundo a qual um país ou região tende a se especializar na produção de bens cujo fator de produção mais abundante é utilizado mais intensivamente.

Os pressupostos do Teorema de HO, adaptadas para o mercado em estudo são:.

As funções de produção com dois fatores - recursos naturais (RN) e capital (K);

A existência de dois bens, pellets $(p)$ e máquinas agrícolas e florestais $(m)$;

Os fatores de produção RN e k possuem completa mobilidade entre os setores produtivos de um mesmo país, sem ônus, e o comércio é livre de barreiras, ou seja, as mercadorias fluem de um país para outro sem custos de transporte, ou qualquer outro impedimento;

As tecnologias de produção são idênticas nos dois países, independente do país e sem custos;

Os fatores de produção são utilizados em combinações diferentes para a produção de (p) e (m). A função de produção de (p) é intensiva em trabalho e a função de produção de $(m)$ é intensiva em capital, tanto interna quanto externamente, apresentando ambas retornos constantes de escala.

A dotação relativa de fatores difere entre países. No Brasil os recursos naturais para produzir pellets é relativamente abundante e na Suécia, o capital é relativamente abundante.

As preferências dos consumidores são iguais nos dois países;

A balança comercial dos dois países está sempre em equilíbrio.

Aplicando esta teoria à análise em questão, tem-se que os estados brasileiros deveriam se especializar no comércio de bens intensivos em recursos naturais e em mão de obra de baixa qualificação, uma vez que estes fatores são abundantes na economia do país. No caso da produção de pellets, os recursos usados são aqueles das atividades agrícolas, agroindústrias e florestais, que podem ser obtidos de forma mais barata do que na Suécia - o país S. Este, por sua vez, teria um parque industrial mais desenvolvido (K), capaz de fornecer máquinas agrícolas e florestais com uma melhor relação custo- benefício ao país $B$, que iria usar esse equipamento para as atividades geradoras de resíduos para a produção de pellets. 


\section{CONCLUSÕES}

O maior problema hoje para os países que são grandes consumidores de pellets é a oferta de matéria-prima tanto para geração de energia térmica (aquecimento) quanto elétrica. $\mathrm{O}$ crescimento do comércio intra-indústria e, consequentemente, do mercado para o produto sobretudo na Europa, aliado a inverno rigoroso em 2005/2006 causou, na Europa, problemas de abastecimento de pellets de madeira. Isso fez os preços subirem, atingindo um pico em Dezembro de 2006, deixando os preços dos pellets e do óleo combustível quase no mesmo patamar estavam quase idênticos.

Dificuldades de fornecimento nos últimos dois anos são basicamente relacionados à falta de estoque de resíduos de madeira. Assim, o potencial do Brasil de entrar no mercado não só como produtor e exportador de pellets de madeira, mas sobretudo de resíduos agrícolas e agroindustriais, é cada vez maior.

O bagaço de cana, gerado como resíduo no processo de transformação da cana de açúcar em álcool, é também outra matéria-prima que pode e deve ser utilizada para pelletização e na produção de etanol de segunda geração, até porque com a expansão da indústria da cana de açúcar no Brasil, a disponibilização desse produto tem sido grande, provocando impactos ambientais pela falta de destinação.

Resolvendo problemas básicos de transporte da matéria prima para a fábrica e do produto já acabado e buscando matérias-primas que dispensem a maior parte do tempo de checagem e tenham, pó isso, um preço mais competitivo, os estudos indicam que o País teria condições de se beneficiar muito com a participação nesse comércio internacional.

\section{REFERÊNCIAS BIBLIOGRÁFICAS}

1. ANEEL - Agencia Nacional de Energia Elétrica. Atlas de Energia Elétrica - 3a ed., Brasília: 2008. Disponível em: http://www.aneel.gov.br/visualizar_texto.cfm?idtxt=1687. Acesso em: $10 / 05 / 2012$.

2. CARASCHI J.C. e GARCIA, D.P. A expansão do mercado de pellets de madeira. : Painel Florestal, fevereiro de 2012. Disponível em_painelflorestal.com.br/.../a-expansao-domercado-de-pellets-de-made...Acesso em 18/05/2012.

3. CORTEZ, L.A.B; LORA, E.E.S.; AYARZA, J.A.C. Biomassa no Brasil e no mundo. In: CORTEZ, L.A.B; LORA, E.E.S.; GOMEZ, E.O. (org). "Biomassa para energia". Campinas, São Paulo. Editora da UNICAMP, 2008.

4. GENTIL, L. V. B. Tecnologia e economia do briquete de madeira. 2008. $196 \mathrm{f}$. Tese (Doutorado em Engenharia Florestal) - Departamento de Engenharia Florestal da Faculdade de Tecnologia da Universidade de Brasília, Distrito Federal, 2008.

5. HALL, D.O.; HOUSE, J. I.; SCRASE, I. Visão geral de energia e biomassa. In ROSILLO-CALE, BAJAY E ROTHMAN. "Uso da Biomassa para Produção de Energia na Indústria Brasileira". Campinas, São Paulo. Editora da UNICAMP, 2005.

6. KAREKESI, S., COELHO, S. T., LATA, K. Traditional Biomass Energy: Improving its Use and Moving to Modern Energy Use. In: International Conference for Renewable Energies, 2004, Bonn. Thematic Background Paper, Alemanha, 2004. 
7. MINISTÉRIO DO MEIO AMBIENTE. Plano Nacional de Resíduos Sólidos: versão preliminar para consulta pública. Brasília, setembro de 2011. Disponível em www.cnrh.gov.br/pnrs/.../versao_Preliminar_PNRS_WM.pdf. Acesso em 09/05/2012.

8. NOGUEIRA, L. A. H. Bioenergias e Sustentabilidade: nexos e métodos. São Paulo, 2005.

9. OLIVEIRA, C.M. Wood Pellets Brasil. Edição eletrônica, 53p. Disponível em http://pt.calameo.com/read/00089539002c2bf637402. Acesso em 17/05/2012.

10. PIGAHT, M. et al. Oportunidades para o comércio de pellets. Revista da Madeira, edição 124, julho de 2010. Disponível em http://www.remade.com.br/br/

11. QUIRINO, W. F. O potencial e aplicação da biomassa na produção da agroindústria. In: I Seminário Internacional de Biomassa e Bioenergia, 2012, São Paulo. Disponível em http://www.avesui.com/seminario/download. Acesso em 11/05/2012b.

12. RAMAGE, J.; SCURLOCK, J. Biomass. In: BOYLE, G. (Ed.). Renewable energy: power for a sustainable future. Oxford: Oxford University Press, cap. 4, p. 137-182, 1996.

13. ROWELL, R. M. USDA-Forest Product Laboratory. Forest Service. Wood Handbook.Chapter 19-Specialty Treatments. Wisconsin. [1987].

14. SERRANO, D.M.C. Avaliação do Potencial de Produção e Exportação de Pellets Combustível no Polo Florestal da Região Sul do Brasil. 2009. 104 f. Dissertação de Mestrado - Faculdade de Engenharia Mecânica da Universidade Estadual de Campinas, SP, 2009.

15. VILLELA, A. A. O dendê como alternativa energética sustentável em áreas degradadas da Amazônia. Dissertação de mestrado. UFRJ/Coppe/PPE, 2009, 175 p. 